monitor, document and report adverse events. Unfortunately, experience demonstrates that this is frequently lacking and can result in the delayed recognition of potentially serious side-effects and interactions.

Khan, I. A. (2002) Clinical and therapeutic aspects of congenital and acquired long QT syndrome. American Journal of Medicine, II2, 58-66.

McKeith, I. G., Gelasko, D., Kosaka, K., et al (1996) Consensus guidelines for the clinical and pathologic diagnosis of dementia with Lewy bodies (DLB): report of a consortium on DLB international workshop. Neurology, 47, III3-III24.

E. Walsh Department of Liaison Psychiatry, Stobhill Hospital, 133 Balornock Road, Glasgow G2I 3UW, UK

\section{The antidepressant debate should move on}

In her editorial Moncrieff (2002) ignored decades of work and focused on a few pieces of research, one of them from 1965. The editorial was followed by a letter criticising this view (Malt, 2002), which was, however, published under the title 'The antidepressant debate continues'. This title might leave the impression that the effectiveness of antidepressants is still questionable.

Some of our colleagues might conclude that antidepressants have no proven effect and their patients should discontinue them. The consequences of such actions have been researched extensively: the relapse rates are approximately twice as high for patients who stop their medication in the first 2-6 months beyond the point of remission, compared with those who continue treatment (e.g. Anderson et al, 2000; Hirschfeld, 2001). Other patients might be denied an effective treatment. Going through all the evidence, which includes comparisons with other treatments and between different classes of antidepressants, animal work, and tryptophan and noradrenalin depletion experiments in people responsive to antidepressants, would be like reinventing the wheel, and is not the subject of this letter. As the rest of us continue to learn of advancements being made to refine and improve the pharmacotherapy of depression, is it possible that there is a group believing that antidepressants really do not have an effect? There is indeed an antidepressant debate - but it is not whether they work but rather how they work that is the current focus of interest.

\section{Declaration of interest}

G.K. and A.K. have received grants from Janssen Research Foundation and GlaxoSmithKline for conducting molecular genetic studies in psychiatric disorders. G.K. has received honoraria from Janssen Cilag for delivering lectures.

\section{Anderson, I. M., Nutt, D. J. \& Deakin, J. F. W. (2000) Evidence-based guidelines for treating depressive disorders with antidepressants: a revision of the 1993 British Association for Psychopharmacology guidelines. Journal of Psychopharmacology, 14, 3-20. \\ Hirschfeld, R. M. A. (200I) Clinical importance of long-term antidepressant treatment. British Journal of Psychiatry, 179 (suppl. 42), s4-s8.}

Malt, U. F. (2002) The antidepressant debate continues (letter). British journal of Psychiatry, 181, 531.

Moncrieff, J. (2002) The antidepressant debate. British Journal of Psychiatry, 180, 193-194.

\section{G. Kirov, A. Korszun Neuropsychiatric}

Genetics Unit, Tenovus Building, University of Wales College of Medicine, Heath Park, Cardiff CFI4 4XN, UK

In her editorial, 'The antidepressant debate', Moncrieff (2002) provocatively questioned the orthodox view that antidepressants are efficacious (i.e. work under clinical trial conditions) in the treatment of depressive illness. Questioning accepted views is valuable but Moncrieff missed the real question, which relates to effectiveness, that is when are antidepressants useful clinically? The efficacy argument at the head of her critique, based on individual, often old and poor-quality, studies flies in the face of consistent findings of antidepressant efficacy in systematic reviews and meta-analyses (e.g. Anderson et al, 2000). Even the argument of bias due to unblinding because of side-effects is contradicted by her own meta-analysis, which showed a significant benefit for antidepressants over 'active' placebo (Moncrieff et al, 1998). Even more compelling is the evidence from continuation/maintenance studies which show that antidepressants have a robust effect in reducing rates of relapse and recurrence (Carney et al, 2001), a cumulative effect over months or years. Explaining this by a placebo effect is difficult to accept, or else demands re-evaluation of the nature of placebo.

This is not to say that 'negative' studies, where antidepressants are no better than placebo, should be ignored. An important factor is probably related to severity of depression. Khan et al (2002) found that the proportion of studies favouring antidepressants over placebo increased with the severity of depression; the response to placebo declined with increasing severity whereas that to antidepressants increased. This raises the fundamental question of when (i.e. at what severity) in real life practice does someone with depression clearly benefit from antidepressant drug treatment. Put another way, is the current trend to wider use of antidepressants for milder depression justified? This can only be answered empirically in appropriate naturalistic trials, and even then will require value judgement about the size of the benefit.

Perhaps the most worrying aspect of Moncrieff's editorial was the implication that we should take either a psychosocial or a physical approach to the treatment of depression. Surely we should have put this rather tired dualist view of psychiatry behind us by now? A holistic view combining drug and psychological treatments is to be preferred and evidence is accumulating that this leads to better outcomes. To conclude, a balanced view of the evidence for antidepressants firmly places them as an established and important therapeutic option (alongside others) in the treatment of depression, with their role becoming more central with increasing severity. The true debate is about the best way to use them.

\section{Declaration of interest}

I.M.A. and P.M.H. have both received honoraria for speaking, been members of advisory boards, received research grants and had support for attending scientific meetings from several pharmaceutical companies involved in the manufacture and marketing of antidepressants.

Anderson, I. M., Nutt, D. J. \& Deakin, J. F.W. (2000) Evidence-based guidelines for treating depressive disorders with antidepressants: a revision of the 1993 British Association for Psychopharmacology guidelines. Journal of Psychopharmacology, 14, 3-20

Carney, S., Geddes, J., Davies, C., et al (2001) Duration of treatment with antidepressants (Cochrane review). Journal of Psychopharmacology, $\mathbf{I 5}$ (suppl.), AI0.

Khan, A., Leventhal, R. M., Khan, R. K., et al (2002) Severity of depression and response to antidepressants and placebo: an analysis of the Food and Drug Administration database. Journal of Clinical Psychopharmacology, 22, 40-45.

Moncrieff, J. (2002) The antidepressant debate. British Journal of Psychiatry, 180, 193-194.

_ Wessely, S. \& Hardy, R. (1998) Meta-analysis of trials comparing antidepressants with active placebos. British Journal of Psychiatry, 172, 227-231. 